\title{
Kinetic analysis of co-combustion of microalgae spirulina platensis and synthetic waste through the fitting model
}

\author{
Sukarni Sukarni ${ }^{1,}{ }^{*}$, Ardianto Prasetiyo ${ }^{2}$, Sumarli Sumarli ${ }^{1}$, Imam Muda Nauri $^{1}$, and Avita \\ Ayu Permanasari $^{1}$ \\ ${ }^{1}$ Center for Renewable and Sustainable Energy Engineering, Department of Mechanical Engineering, \\ State University of Malang, 65145 Malang, Indonesia \\ ${ }^{2}$ Master Program of Mechanical Engineering, Graduate School, State University of Malang, 65145 \\ Malang, East Java Indonesia
}

\begin{abstract}
Thermogravimetric analyzer had been occupied to investigate the behavior of co-combustion between microalgae Spirulina platensis and synthetic waste. The powder of microalgae and synthetic waste were mixed in the same ratio of 50/50. Around $10 \mathrm{mg}$ of the sample was heated up in the chamber under air atmosphere flowrate of $100 \mathrm{ml} / \mathrm{min}$ at a heating rate of $10{ }^{\circ} \mathrm{C} / \mathrm{min}$. The results showed that the sample blend is undergoing thermal degradation in the three stages. The most massive reaction occurred in the second stage in which around $74 \%$ of the mass degraded and combusted. The activation energy in the main combustion reaction zone according to the method of Horowitz-Metzger was 57.77 $\mathrm{kJ} / \mathrm{mol}$.
\end{abstract}

\section{Introduction}

Depleting fossil-based energy and global warming issue encourage research on renewable and environmentally friendly energy resource. Microalgae to be one of the candidates that draw the passionate researcher interest because of it has a high ability to multiplying the biomass [1]. Moreover, from the environmental perspectives, microalgae become a future promoting biomass fuel due to it would convert $\mathrm{CO}_{2}$ twice more than the resulted biomass during the photosynthesis process $[2,3]$. Hence it reflects to be $\mathrm{CO}_{2}$-neutral fuels when the biomass being burned [4].

In addition, the environmental issue in accordance with the massive increasing amount of waste has been generating a crucial problem in all developing cities of Indonesia. As a consequence of urban development and their lifestyle orientation changes, at around $97,356,208 \mathrm{~kg}$ of waste have been growth per day in Indonesia. The synthetic waste (SW) especially plastic has growth in the rate of $10,660,505 \mathrm{~kg} /$ day $[5,6]$. This enormous amount of waste requires proper handling in order to dispose safely and to generate economic value-added. Converting waste to energy become an attractive choice owing to significant volume reduction of $95 \%$ as well as mass decreasing till to $90 \%$ [7, 8]. Moreover, appropriate waste burning technique led to significant energy recovery, reducing landfilling space and decreasing the negative environmental impact [9].

\footnotetext{
* Corresponding author: sukarni.ft@um.ac.id
} 
Study on microalgae combustion has been performed by several researchers. Single species combustion of Chlorella vulgaris [4], Nannochloropsis gaditana [10], Scenedesmus almeriensis [11] and Nannochloropsis oculata [2] resulted in different thermal decomposition pattern which is possible due to differences in the content of organic and mineral compounds of every species. However, from the current literature review, combustion of Spirulina platensis (SP) has not been found. Meanwhile, co-combustion of Chlorella protothecoides and rice straw [12], lignocellulosic and Scenedesmus almeriensis biomasses [11], Chlorella vulgaris and textile dyeing sludge [13] indicated that the blending could improve their combustion performance. However, most of the aforementioned literature focused on co-combustion with plantation biomass or by-product of the textile industry, while co-combustion of microalgae with SW was seldom been studied. In-depth understanding on co-combustion of microalgae and SW can be broadening utilization way of microalgae and SW as well as addressing the problem of raising $\mathrm{SW}$.

The kinetics data of thermal processes are a critical parameter for determining the proper combustion technique. In order to gain this data, the thermogravimetric (TG) analysis has been massively employed. Several combustion characteristic parameters such as degradation profile of the material, the temperature of initial burning and temperature of burnout as well as the kinetics parameters including activation energy, pre-exponential factor, and reaction order can be generated from TG data. Those above parameters are of great significance for enhancing understanding of co-combustion of microalgae and synthetic waste, which they can subsequently be applied for establishing the optimum operation of the furnace.

This paper presented the co-combustion behavior of microalgae SP and SW in relation with the material decomposition in the course of heating during the combustion process in the TG analyzer. Based on TG data, subsequently, the kinetic parameters were evaluated through the fitting method of Horowitz-Metzger.

\section{Materials and method}

\subsection{Materials preparation}

The origin of SP was provided by the Center for Development of Brackish Water Aquaculture (Balai Besar Pengembangan Budidaya Air Payau-BBPBAP), Jepara, Indonesia. The drying oven was occupied for the drying out the water at $100{ }^{\circ} \mathrm{C}$ for $24 \mathrm{~h}$. The dry biomass then pulverized and subsequently stored in the insulated bottle.

The SWs have randomly collected from dumpsters in Malang city (East Java province, Indonesia). These waste consist of mineral bottles, mattresses, styrofoam, detergent packs, plastic bags, banners, jeans, rice bags, water pipes, shampoo bottles, rice wrapper plastic, flip-flops, oil bottles, sponges, synthetic leather, motorcycle body, bottle of floor cleaner liquid, jerry cans of water, and various thick plastic. These samples were thoroughly cleaned and sun-dried for two days during the dry season. The dried samples were subsequently grounded to less than $1 \mathrm{~mm}$ and then stored in a vacuum bottle. Prior to testing, a component of SP and SW was mixed with the mass ratio of 50:50 (wt,\%).

\subsection{Thermogravimetric test}

METTLER TOLEDO TGA/DSC1 simultaneous analyzer was occupied to study thermal degradation of the sample under a heating rate of $10{ }^{\circ} \mathrm{C} / \mathrm{min}$ and air atmosphere flow rate of $100 \mathrm{ml} / \mathrm{min}$. A small sample at around $10 \mathrm{mg}$ was loaded into the ceramic crucible in order 
to avoid the effect of mass and heat transfer limitation. The atmosphere air was continuously flowed into the inner part of the furnace at a rate of $100 \mathrm{ml} / \mathrm{min}$ during the combustion process. The sample was subjected into the pre-adjusted heating program from room temperature till to $1000{ }^{\circ} \mathrm{C}$. The respective TG and DSC (differential scanning calorimetry) data were resulted during the experiment, and subsequently, DTG (derivative thermogravimetric) data was generated as the first derivative of TG.

\subsection{Kinetics method}

The most literature reported that the kinetics calculation of combustion reactions are examined as a first-order reaction for the purpose of simplification in the analysis. Actually, the combustion process of biomass individually or its blend with other fuel is the more complicated chemical reaction in which each element was decomposed and oxidized at different temperature led to solid-gas phase or gas phase reactions. For that reason, this study adopted different $\mathrm{g}(\alpha)$ model to evaluate the activation energy, reaction order and frequensi factor through the use of Horowitz-Metzger model.

The solid material was undergoing thermal degradation during the experiment, and its reaction rate can be represented as the following Arrhenius equation:

$$
\frac{d \alpha}{d t}=A \exp \left(\frac{-E}{R T}\right) f(\alpha)
$$

where $A$ is frequency factor $\left(\mathrm{s}^{-1}\right)$, is the activation energy $(\mathrm{kJ} / \mathrm{mol})$, is the universal gas constant $(8.314 \mathrm{~J} / \mathrm{mol} \mathrm{K}), T$ is the absolute reaction temperature $(\mathrm{K}), f(\alpha)$ expressed the supposed model of the reaction mechanism, and $\alpha$ is lost mass fractions.

Equation (1) expressed the isothermal reaction rate. This experiment was performed under the non-isothermal condition; hence for this situation, heating rate can be specified as Substitution Equation (1) with $d t=d T / \beta$ resulted in equation that represented the nonisothermal kinetic equation as folow:

$$
\frac{d \alpha}{d T}=\frac{A}{\beta} \exp \left(\frac{-E}{R T}\right) f(\alpha)
$$

By selecting the model of the th order reaction, then $f(\alpha)=(1-\alpha)^{\mathrm{n}}$ and Equation (2) can be expressed as:

$$
\frac{d \alpha}{(1-\alpha)^{n}}=\frac{A}{\beta} \exp \left(\frac{-E}{R T}\right) d T
$$

where is a conversions (lost mass fractions) and it is represented as:

where:

$$
\alpha=\frac{m_{\mathrm{i}}-m_{\mathrm{t}}}{m_{\mathrm{i}}-m_{f}}
$$

$\mathrm{m}_{\mathrm{i}}$ is the initial mass that refers to the early of the mass event of interest;

$\mathrm{m}_{\mathrm{t}}$ is the actual mass of the sample at time $t$;

$\mathrm{m}_{\mathrm{f}}$ is the final mass that refers to the end of the mass event of interest.

\section{Results and discussion}

\subsection{Thermal characteristic}

The TG, DTG, and DSC curves of the SP/SW sample at a heating rate of $10{ }^{\circ} \mathrm{C} / \mathrm{min}$ was depicted in Figure 1. It was obviously observed that $\mathrm{SP} / \mathrm{SW}$ decomposed into three stages in the course of heating during the combustion process from ambient temperature till to $1000^{\circ} \mathrm{C}$.

The stage which was characterized by material decomposition started at ambient temperature and finished at around $176{ }^{\circ} \mathrm{C}$, was the first stage. This temperature range was relevant to the moisture evaporation and degradation a small part of the material formed 
very light volatile. At around $2.8 \%$ mass of the material was decomposed in the first stage. It indicated that $\mathrm{SP} / \mathrm{SW}$ blends containing a small portion of moisture, where this was preferable material as being fuel feedstock.

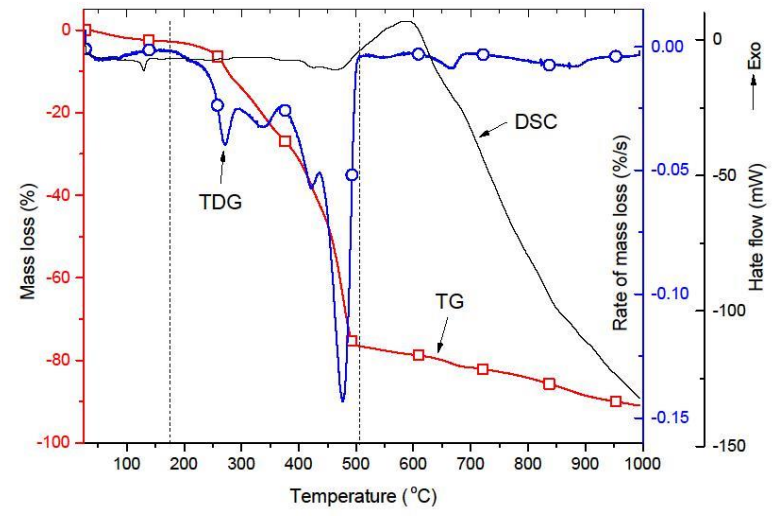

Fig. 1. The TG, DTG, and DSC curves of the $\mathrm{SP} / \mathrm{SW}$ at a heating rate of $10^{\circ} \mathrm{C} / \mathrm{min}$.

Linear with the escalating temperature, heat exposure on materials increases led to promote a massive degradation of the solid. This was occurred in the second stage, in which around $74 \%$ of the solid was decomposed and volatilized and then combusted. This stage was recognized by the appearance of steep declining of TG curve and emergence the prominent basin of DTG curve at range temperature of $176-507{ }^{\circ} \mathrm{C}$. This was associated with the volatile-releasing and burning and sequentially continuous with the char combustion.

The last stage was characterized by undistinguished declining of TG curve. It indicated that very slow decomposition and oxidation of remaining char was continued in this stage, denoted by the emergence of the significant hump on DSC curve till to temperature of 595 ${ }^{\circ} \mathrm{C}$. Beyond the temperature $595{ }^{\circ} \mathrm{C}$, steep declining slope appearance on DSC curve up to the final temperature of $1000{ }^{\circ} \mathrm{C}$. It possibly because of the degradation of mineral matter that naturally consists in the biomass origin requires a certain amount of heat led to an endothermic reaction.

\subsection{Calculation of kinetic parameters}

The calculation of kinetic parameters was performed by assuming that combustion reaction was a separate reaction that took place at a certain temperature zone as a single step reaction of the th order. Based on TG and DTG curves in Figure 1, it could be observed the initial temperature $\left(T_{i}\right)$ of reaction, the burnout temperature $\left(T_{f}\right)$, and temperature of maximum rate $\left(T_{m}\right)$, in which the material degraded at the highest rate $\left(M_{m}\right)$ as well as the mass loss at a certain zone of the mass event of interest. The overall aformentioned characteristics were depicted in the Table 1.

Table 1. Characteristic parameters of $\mathrm{SP} / \mathrm{SW}$ combustion at $10^{\circ} \mathrm{C} / \mathrm{min}$.

\begin{tabular}{|c|c|c|c|c|}
\hline \multicolumn{5}{|c|}{ Characteristic parameters } \\
\hline $\mathrm{T}_{\mathrm{i}}\left({ }^{\circ} \mathrm{C}\right)$ & $\mathrm{T}_{\mathrm{f}}\left({ }^{\circ} \mathrm{C}\right)$ & $\mathrm{T}_{\mathrm{m}}\left({ }^{\circ} \mathrm{C}\right)$ & $\mathrm{M}_{\mathrm{m}}\left({ }^{\circ} \mathrm{C}\right)$ & Mass loss $(\%)$ \\
\hline 176 & 507 & 476 & 0.143 & 74 \\
\hline
\end{tabular}

Applying the Horowitz-Metzger method into Equation (3) resulted in the linear equation as follow:

Where:

$$
\ln g(\alpha)=\left(\ln \left(\frac{A R T_{M}^{2}}{\beta E}\right)-\frac{E}{R T_{m}}\right)+\frac{E \varphi}{R T_{M}^{2}}
$$




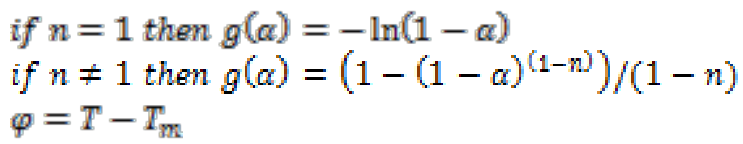

Using any $n$ values for obtaining the value of $\ln g(\alpha)$ at the conversion range $(\alpha)$ between $0.05-0.95$, subsequently can be plotted $\ln g(\alpha)$ versus $\varphi$ to generate a coeffisien correlation $\mathrm{R}^{2}$. The most suitable $n$ would be implied in the best linier plot of $\ln g(\alpha)$ versus $\varphi$. For that reason, $\mathrm{R}^{2}-n$ curve was drawn as depicted in the Figure 2, and then the curve's peak represented the highest value of $\mathrm{R}^{2}$, in which it in correlation with the most appropriate $n$.

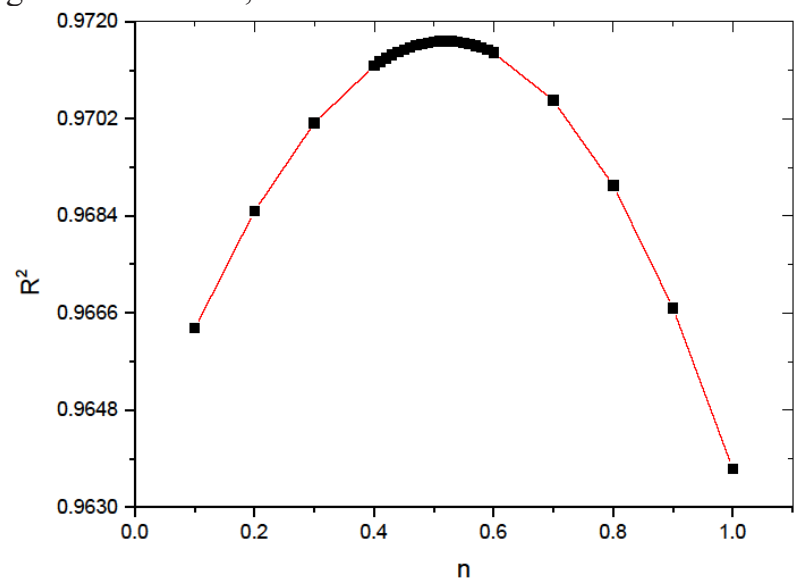

Fig. 2. The $\boldsymbol{R}^{2}-\boldsymbol{n}$ curve in accordance with the Horowitz-Metzger method.

Figure 2 indicated the highest $R^{2}=0.972$ in accordence with the reaction order $n=0.52$. This most appropriate value then was applied to create a final plot of $\ln g(\alpha)$ versus $\varphi$ as shown in the Figure 3. The respective activation energy and the frequency factor were calculated from the slope and intercept. The kinetic parameters resulted from the final plot was tabulated in the Table 2.

Table 2. The kinetics parameters of SP/SW combustion calculated by Horowitz-Metzger method.

\begin{tabular}{|c|l|c|c|c|c|}
\hline $\boldsymbol{\beta}\left({ }^{\mathbf{C}} \mathbf{C} / \mathbf{m i n}\right)$ & $\begin{array}{l}\text { Trendline } \\
\text { equation }\end{array}$ & $\boldsymbol{R}^{\mathbf{2}}$ & \multicolumn{3}{|c|}{ Kinetics paramters } \\
\cline { 4 - 6 } & & & $\boldsymbol{E}(\mathbf{k J} / \mathbf{m o l})$ & $\begin{array}{c}\mathbf{L o g} \boldsymbol{A} \\
(\mathbf{1} / \mathbf{m i n})\end{array}$ & $\boldsymbol{n}$ \\
\hline 10 & $\begin{array}{l}y=0.0124 x+ \\
0.1551\end{array}$ & 0.972 & 57.77 & 3.19 & 0.52 \\
\hline
\end{tabular}

Table 2 showed that activation energy of SP/SW blend was $57.77 \mathrm{~kJ} / \mathrm{mol}$. This value was lower than that of Scenedesmus almeriensis/corn blend that was $171.9 \mathrm{~kJ} / \mathrm{mol}$ [11], comparable with Chlorella protothecoides/waste (5/5) that was $54.46 \mathrm{~kJ} / \mathrm{mol}$ [14], and higher than Tetraselmis suecica/coal (5/5) that was around $47 \mathrm{~kJ} / \mathrm{mol}$ [15]. The activation energy was an essential standard in which the reactivity of solid fuel was determined; higher activation energy indicated that the solid less in reactivity and vise versa. 


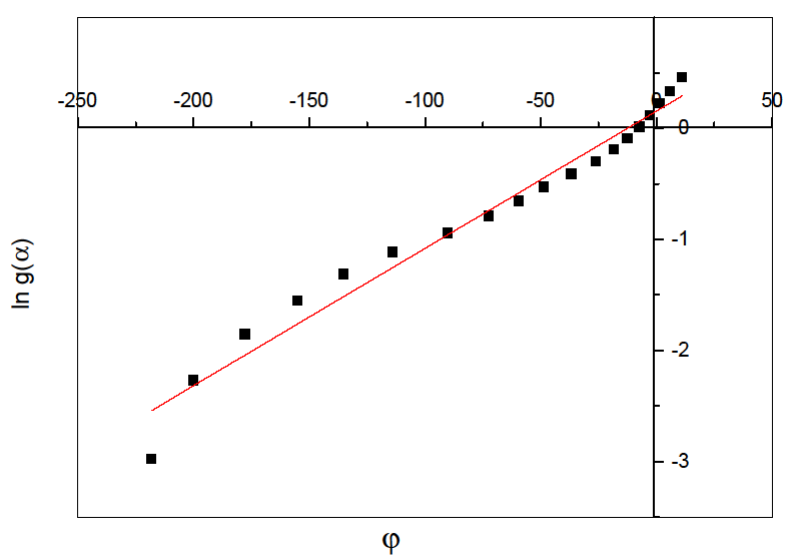

Fig. 3. Linear regression of the plot $\ln g(\alpha)$ versus $\varphi$ according to the Horowitz-Metzger method.

\section{Conclusion}

The co-combustion behavior of microalgae Spirulina platensis and synthetic waste (a blend of 50/50) have been studied. This blend was decomposed into three stages during the combustion process with the highest mass loss taken place in the second stage. The reaction kinetics evaluation by using the Horowitz-Metzger method resulted in activation energy, logarithmic of pre-exponential factor and reaction order of this blend were $57.77 \mathrm{~kJ} / \mathrm{mol}$, $3.19 / \mathrm{min}$ and 0.52 , in that order.

This research supported by Directorate of Research and Community Services, Ministry of Research, Technology, and Higher Education, Government of Indonesia under the scheme of the Superior Basic Research of Higher Education with Grant Number 26.3.35/UN32.14/LT/2018).

\section{References}

1. Sukarni, Sudjito, N. Hamidi, U. Yanuhar, I. N. G. Wardana, Int. J. Energy Environ. Eng. 5, 279- 290 (2014)

2. Sukarni, Sudjito, N. Hamidi, U. Yanuhar, I. N. G. Wardana, Front. Energy. 9, 125133 (2015)

3. S. Sukarni et al., J. Appl. Res. Technol. 16, 53-66 (2018)

4. C. Chen, X. Ma, K. Liu, Appl. Energy. 88, 3189-3196 (2011)

5. J. R. Jambeck et al., Science (80-. ). 347, 768-771 (2015).

6. Sukarni, Sumarli, P. Puspitasari, H. Suryanto, R. F. Wati, AIP Conference Proceedings, 1887, p. 020066 (2017)

7. C. Montejo, C. Costa, P. Ramos, M. D. C. Márquez, Appl. Therm. Eng. 31, 21352140 (2011)

8. M. Li et al., Fuel. 83, 1397-1405 (2004)

9. S. Sukarni, in AIP Conference Proceedings, 1778, p. 020003 (2016)

10. L. Sanchez-Silva, D. López-González, A. M. Garcia-Minguillan, J. L. Valverde, Bioresour. Technol. 130, 321-331 (2013)

11. R. López, C. Fernández, X. Gómez, O. Martínez, M. E. Sánchez, J. Therm. Anal. Calorim. 114, 295-305 (2013) 
12. Y. Tang, X. Ma, Z. Lai, Q. Yu, Int. J. Energy Res. 42, 532-541 (2018)

13. X. Peng, X. Ma, Z. Xu, Bioresour. Technol. 180, 288-295 (2015) 